\title{
REVIEW
}

\section{Treatment with echinocandins during continuous renal replacement therapy}

\author{
Francisco Javier González de Molina*, Maria de Los Ángeles Martínez-Alberici and Ricard Ferrer
}

\begin{abstract}
Echinocandins are indicated as first-line treatment for invasive candidiasis in moderate to severe illness.

As sepsis is the main cause of acute kidney injury, the combination of echinocandin treatment and continuous renal replacement therapy (CRRT) is common. Optimizing antibiotic dosage in critically ill patients receiving CRRT is challenging. The pharmacokinetics of echinocandins have been studied under various clinical conditions; however, data for CRRT patients are scarce. Classically, drugs like echinocandins with high protein binding and predominantly non-renal elimination are not removed by CRRT, indicating that no dosage adjustment is required. However, recent studies report different proportions of echinocandins lost by filter adsorption. Nevertheless, the clinical significance of these findings remains unclear.
\end{abstract}

\section{Review \\ Introduction}

Echinocandins are the first systemic antifungal agents that selectively target the fungal cell [1]. Three echinocandins are currently available: caspofungin, anidulafungin, and micafungin [2]. Echinocandins are cyclic hexapeptides with N-linked acyl lipid side chains. These lipophilic side chains predominantly differentiate the three echinocandins, resulting in variations in solubility, microbiological potency, and pharmacokinetic disposition [3-5]. Echinocandins are indicated as first-line antifungal treatment for invasive candidiasis in patients with moderately severe to severe illness [6].

The mechanism of action of the echinocandins is the non-competitive inhibition of $\beta$-(1,3)-D-glucan synthase [7], an essential component of many fungal cell walls, leading to osmotic instability and cell death $[5,8]$.

\footnotetext{
* Correspondence: fgonzalez@mutuaterrassa.es

Intensive Care Department, Hospital Universitari Mútua de Terrassa, Universitat de Barcelona, Plaça Dr. Robert, E-08221 Terrassa, Spain
}

Echinocandins exhibit fungistatic activity against Aspergillus species and concentration-dependent fungicidal activity against Candida species with a prolonged post-antifungal effect [9-11]. Acquired resistance to the echinocandins remains sporadic [12]. Both maximum concentration/minimum inhibitory concentration $\left(\mathrm{C}_{\max } / \mathrm{MIC}\right)$ and $\mathrm{AUC}_{0-24} /$ MIC (area under the curve over 24-hour dosing interval/ MIC) have been associated with efficacy [13-15]. All echinocandins are highly protein-bound and have a low to moderate volume of distribution and very low excretion as unchanged drug in the urine $[14,16]$. Echinocandins have an excellent safety profile and low potential for pharmacological interactions $[17,18]$.

Acute renal failure is a common complication of critical illness and carries a high mortality [19,20]. It affects up to $20 \%$ of critically ill patients with severe sepsis or septic shock [21-23]. These patients usually receive continuous renal replacement therapy (CRRT) and antibiotics simultaneously $[24,25]$. Antimicrobial pharmacokinetics are affected by CRRT and may be altered by acute renal failure and critical illness [26]. Several factors should be considered in antibiotic prescription under CRRT: pharmacokinetics, causative microorganism, MIC, renal replacement therapy mode, membrane and surface area, sieving coefficient, effluent and dialysate rates, and others. Only the unbound fraction of a drug is available for filtration, and drugs with high protein binding are largely unaffected by CRRT. The degree of protein binding is the most important factor influencing whether a drug needs dose adjustment during CRRT. Drugs that are more than $90 \%$ bound to plasma proteins are unlikely to be removed by hemodialysis and hemofiltration [27-31], but the adsorption on the membrane in the filter could result in a significant clearance [32-35].

\section{Drug adsorption clearance in continuous renal replacement therapy}

Adsorption of antibiotics onto CRRT filters may result in drug elimination [36-44]. Most research on adsorption to CRRT filters has focused on the cytokines 
[45-52]. Few studies have investigated the adsorption of antibiotics onto CRRT filters, so the clinical importance of this phenomenon is unknown and is not taken into account in drug guidelines $[27,30,31,53,54]$ or in clinical pharmacokinetic/pharmacodynamic (pK/pD) studies [55].

Adsorptive clearances depend on the selective or nonselective binding of molecules to the filter membrane. The adsorptive capacity for low-molecular-weight plasma proteins varies among different hemofilter membrane materials [35,56,57]. Adsorptive clearances for middle molecules are time-dependent, with maximum values occurring in the first few hours of therapy [58]. Adsorption onto filters is a saturable process that varies according to the timing of the filter changes, so that adsorption immediately after a filter change will be greater than 48 hours after a filter change. Thus, measuring drug concentrations close to the time of a filter change may alter estimates of clearance and should be avoided. If adsorption is reversible when circulating drug concentrations fall, the maximum adsorption during CRRT will be underestimated.

\section{Effect of membrane characteristics}

The membranes used in CRRT are high-flux synthetic membranes, mainly made of polysulfone, polyamide, polyacrylonitrile (PAN), or polymethyl methacrylate. These membranes can be asymmetric or symmetric, and their thickness ranges from 40 to $100 \mu \mathrm{m}$. Hemofilter membranes made of PAN or polymethyl methacrylate are symmetric in structure, whereas those made from polysulfone or polyamide are asymmetric [59,60]. All these synthetic membranes are hydrophobic, and their pores allow passage of molecules ranging from 10 to 30,000 daltons. This pore size allows a high rate of ultrafiltration under relatively small pressures. These membranes have high sieving coefficient/saturation coefficients $\left(\mathrm{S}_{\mathrm{c}} / \mathrm{S}_{\mathrm{d}}\right)$ for solutes in a wide range of molecular weights (0 to 20,000 daltons), and this further contributes to high drug and metabolite clearance [59,61]. Another aspect that influences adsorption is the membrane's electrical charge [57]. Whereas polysulfone and polyamine hemofilters have no net charge, PAN filters have a negative charge. This last characteristic of hemofilters may influence adsorption and retention of drugs to negatively charged hemodialyzer membranes $[62,63]$. Moreover, if adsorption is due to ion interaction between the antibiotic and hemofilter, $\mathrm{pH}$ can affect drug adsorption to some filter membranes; for example, aminoglycosides and levofloxacin are significantly adsorbed by PAN membranes [38-40]. The extent of drug adsorption also depends on hemofilter surface area. It is reasonable to think that increasing surface area will increase the amount of drug adsorbed and may also increase the time to maximum adsorption. Adsorption to hemofilters varies with the materials used in their membranes. Different hollow fibers have different adsorptive capacities. Some filter membranes, such as those made from the commonly used PAN, may adsorb a substantial amount of drug to their surface compared with polyamine filter membranes $[37,64]$.

\section{Effect of albumin on drug adsorption}

Antibiotics vary largely in protein binding $[65,66]$. While aminoglycosides bind poorly to proteins, the percentage of echinocandins bound to proteins in serum exceeds $90 \%$. The binding capacity of albumin is decreased not only in chronic kidney disease but also in acute renal failure. Other unknown factors include the effect of increased volume of distribution because of edema in critically ill patients and the possible impact of albumin concentration and protein binding on adsorption.

\section{Effect of continuous renal replacement therapy mode and flows}

Transmembrane pressure may be an important determinant of adsorption. Membrane pores are structured like 'water channels'. When the transmembrane pressure increases, the channels may open, resulting in an increase in the number of potential adsorptive sites $[67,68]$. Finally, the effects on adsorption of possible interactions between drugs and acute-phase proteins such as $\alpha 1$-acid glycoprotein, cytokines, and complement factors are unknown.

\section{Studies on echinocandins and continuous renal replacement therapy \\ Caspofungin}

Weiler and colleagues [42] have recently investigated the influence of continuous venovenous hemofiltration (CVVHF) and continuous venovenous hemodialysis (CVVHD) on the pharmacokinetics of caspofungin in critically ill patients in order to assess the appropriateness of standard dosage during CRRT (Table 1). The effects of CVVHD and CVVHF on caspofungin clearance, in order to detect an eventual adsorption, were assessed by determination of $S_{c}, S_{d}$, and the difference between caspofungin concentrations in the hemofilter/dialyzer inlet and outlet $\left(\mathrm{C}_{\text {in }}-\mathrm{C}_{\text {out }}\right)$. CRRT was performed with polysulfone hemofilters $\left(0.71 \mathrm{~m}^{2}\right.$ for CVVHF and $1.8 \mathrm{~m}^{2}$ for CVVHD). Sampling was performed on day 1 of caspofungin treatment (single dose) and at steady state on day 4 or later. Blood samples were drawn from an arterial line at $1,2,4,8,12$, and 24 hours after the start of caspofungin infusion. For patients on CRRT, ultrafiltrate/dialysate samples were taken simultaneously. In addition, blood samples from the $\mathrm{C}_{\mathrm{in}}-\mathrm{C}_{\text {out }}$ were collected at 1 and 24 hours. Caspofungin was quantified in plasma samples by a liquid chromatography/mass 
Table 1 Comparison of pharmacokinetic parameters of echinocandins in patients receiving and not receiving continuous renal replacement therapy

\begin{tabular}{|c|c|c|c|c|c|c|}
\hline & & \multicolumn{5}{|c|}{ Pharmacokinetic parameter } \\
\hline & & $C_{\max }, \mu g / m L$ & $\begin{array}{c}\mathrm{AUC}_{0-24 h} \\
\mu \mathrm{g} \cdot \text { hour } / \mathrm{mL}\end{array}$ & $\begin{array}{c}t_{1 / 2} \\
\text { hours }\end{array}$ & $\mathrm{CL}_{\mathrm{T}}$ & $v_{d}$ \\
\hline \multirow{4}{*}{$\begin{array}{l}\text { PK studies in patients not } \\
\text { receiving CRRT }\end{array}$} & Caspofungin [69] ${ }^{a}$ & 12.04 & 96.01 & 9.29 & $0.59 \mathrm{~L} / \mathrm{hour}$ & $\mathrm{N} / \mathrm{A}$ \\
\hline & Anidulafungin $[70]^{\mathrm{b}}$ & 7.2 & 110.3 & $24-26$ & $1.0 \mathrm{~L} /$ hour & $34.5 \mathrm{~L}$ \\
\hline & Micafungin $[71]^{c}$ & 7.1 & 59.9 & 13.0 & $1.25 \mathrm{~L} /$ hour & $23.0 \mathrm{~L}$ \\
\hline & Weiler et al. [42] ${ }^{d}$ & & & & & \\
\hline \multirow{12}{*}{$\begin{array}{l}\text { PK studies in patients receiving } \\
\text { CRRT }\end{array}$} & Single doses (CWHF) & 8.4 & 91 & 11.7 & $\begin{array}{l}7.8 \mathrm{~mL} / \mathrm{hour} \\
\text { per kg }\end{array}$ & $\begin{array}{c}138 \mathrm{~mL} / \\
\mathrm{kg}\end{array}$ \\
\hline & Single doses (CWHD) & 8.2 & 76 & 12.4 & $\begin{array}{l}9.8 \mathrm{~mL} / \text { hour } \\
\text { per kg }\end{array}$ & $\begin{array}{c}175 \mathrm{~mL} / \\
\mathrm{kg}\end{array}$ \\
\hline & $\begin{array}{l}\text { Single doses in patients not } \\
\text { receiving CRRT }\end{array}$ & 7.3 & 58 & 9.5 & $\begin{array}{l}10.8 \mathrm{~mL} / \text { hour } \\
\text { per kg }\end{array}$ & $\begin{array}{c}135 \mathrm{~mL} / \\
\mathrm{kg}\end{array}$ \\
\hline & Steady-state (CWHF) & 11.0 & 107 & 12.4 & $\begin{array}{c}5.3 \mathrm{~mL} / \text { hour per } \\
\mathrm{kg}\end{array}$ & $97 \mathrm{~mL} / \mathrm{kg}$ \\
\hline & Steady-state (CWHD) & 10.8 & 141 & 15.2 & $\begin{array}{l}4.2 \mathrm{~mL} / \mathrm{hour} \\
\text { per kg }\end{array}$ & $89 \mathrm{~mL} / \mathrm{kg}$ \\
\hline & $\begin{array}{l}\text { Steady-state in patients not } \\
\text { receiving CRRT }\end{array}$ & 8.8 & 100 & 12.6 & $\begin{array}{l}4.9 \mathrm{~mL} / \mathrm{hour} \\
\text { per kg }\end{array}$ & $\begin{array}{l}104 \mathrm{~mL} / \\
\mathrm{kg}\end{array}$ \\
\hline & Leitner et al. [36] ${ }^{e}$ & 8.5 & 109.9 & 28.8 & NR & $42 \mathrm{~L}$ \\
\hline & De Rosa et al. $[72]^{f}$ & $5.68-9.04$ & $67.48-98.18$ & $\begin{array}{l}15.34- \\
31.99\end{array}$ & 1.48-2.6 L/hour & $\begin{array}{l}32.81- \\
48.48 \mathrm{~L}\end{array}$ \\
\hline & Kishino et al. [73] ${ }^{g}$ & 6.31 & 50.04 & 13.63 & $0.59 \mathrm{~L} / \mathrm{hour}$ & $11.53 \mathrm{~L}$ \\
\hline & Hirata et al. [43] ${ }^{\text {h }}$ & & & & & \\
\hline & Patients receiving CRRT & N/A & N/A & N/A & $1.4 \mathrm{~L} /$ hour & $17.5 \mathrm{~L}$ \\
\hline & Patients not receiving CRRT & N/A & $\mathrm{N} / \mathrm{A}$ & N/A & $1.4(\mathrm{~L} /$ hour & $16.2 \mathrm{~L}$ \\
\hline
\end{tabular}

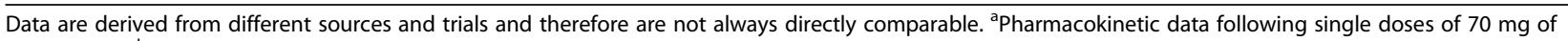

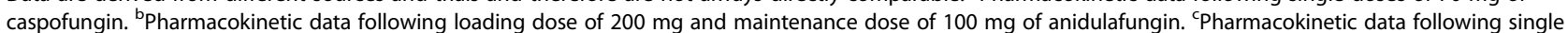
doses of $100 \mathrm{mg}$ of micafungin. ${ }^{\mathrm{d}}$ Pharmacokinetics of caspofungin (single doses and steady-state) in critically ill patients on continuous venovenous hemofiltration

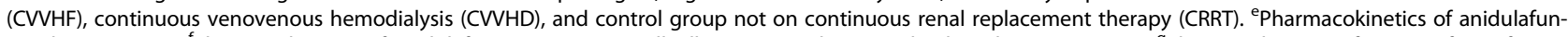

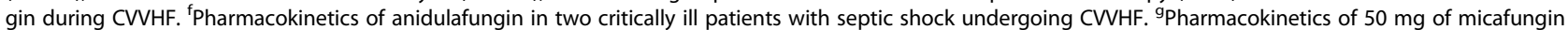
(steady-state) in living donor liver recipients receiving CVVHF. ' $\mathrm{P}$ harmacokinetics of micafungin (150-300 mg) in patients on continuous venovenous hemodiafiltration and not receiving CRRT. AUC ${ }_{0-24}$, area under the curve over 24-hour dosing interval; $\mathrm{CL}_{\mathrm{T}}$, total clearance $(\mathrm{L} / \mathrm{h}$ or $\mathrm{mL} / \mathrm{hour}$ per $\mathrm{kg})$; $\mathrm{C}_{\text {max }}$, maximum concentration; N/A, not available; NR, not reported; PK, pharmacokinetic; $t_{1 / 2}$, elimination half-life; $V_{d}$, volume of distribution $(L$ or $\mathrm{mL} / \mathrm{kg})$.

spectroscopy method (online SPE-LC-MS/MS). Thirtysix plasma sample sets were obtained from 27 patients (14 patients on CRRT and 13 patients off CRRT). Assessment under both single-dose and steady-state conditions was possible for only eight patients. Six sets of ultrafiltrate samples were drawn from patients on CVVHF. Ultrafiltrate concentrations amounted to only $0.33 \%$ of the respective plasma levels; that is, the median (range) $\mathrm{S}_{\mathrm{c}}$ was $0.0033(0.0157)$. The hemofiltration clearance (CLHF) calculated from $S_{c}$ was as low as 8.0 (37.8) $\mathrm{mL} /$ hour $(1.8 \%(9.6 \%)$ of total clearance). When estimated from $C_{\text {in }}-C_{\text {out }}$, the CLHF was higher (61.0 $(10,712.2) \mathrm{mL} /$ hour$)$. Dialysate sampling was performed during all 11 sampling periods in patients on CVVHD. The $S_{d}$ was $0.0027(0.2470)$, yielding a hemodialysis clearance (CLHD) of 5.9 (530.5) mL/hour (2.5\% (66.5\%) of the total caspofungin clearance). The CLHD calculated from $C_{\text {in }}-C_{\text {out }}$ amounted to $5.5(1,550.5) \mathrm{mL} /$ hour. The authors concluded that the influence of CRRT on caspofungin elimination appears to be negligible, and the standard dosage is probably appropriate for ICU patients on CRRT.

\section{Anidulafungin}

In 2011, Leitner and colleagues [36] provided data on the adsorptive capacity of hemofilters for echinocandins from a study of 10 patients undergoing CVVHF for acute kidney injury by using a $1.2 \mathrm{~m}^{2}$ polysulfone hemofilter. The ultrafiltration rate was $25 \mathrm{~mL} / \mathrm{min}$. Anidulafungin was infused on 3 consecutive days, starting with a loading dose of $200 \mathrm{mg}$ on day 1 , followed by doses of $100 \mathrm{mg} /$ day. On days 1, 2, and 3, blood samples were taken from the arterial and venous lines of the extracorporeal circuit before the start and at the end of the infusion as well as at 2, 4, 6, 8, and 24 hours after infusion; at the same time points, ultrafiltrate samples were 
collected. The concentration of anidulafungin in plasma and ultrafiltrate was assessed by high-performance liquid chromatography. Eight patients completed the scheduled 3-day CVVHF treatment. Pre-filter $C_{\max }(8.5 \pm 3.6 \mathrm{mg} / \mathrm{L})$ was reached 3 hours after the start of infusion. After the $100 \mathrm{mg}$ dose on days 2 and $3, \mathrm{C}_{\max }$ values were $6.5 \pm 3.1$ $\mathrm{mg} / \mathrm{L}$ and $5.9 \pm 2.0 \mathrm{mg} / \mathrm{L}$, respectively. Mean minimum concentration $\left(C_{\min }\right)$ values were $3.1 \pm 1.5,3.0 \pm 1.0$, and $2.9 \pm 1.1 \mathrm{mg} / \mathrm{L}$ at 24,48 , and 72 hours, respectively. Maximal differences in anidulafungin concentrations between the venous and arterial port (AV differences) were measured at 2 hours $(19 \% \pm 6 \%)$; AV differences steadily decreased to $14 \% \pm 4 \%$ at 24 hours, $10 \% \pm 2 \%$ at 48 hours, and $9 \% \pm 2 \%$ at 72 hours. The mean arterial $\mathrm{AUC}_{0-24}$ was $109.9 \pm 49.82 \mathrm{mg} \cdot \mathrm{h} / \mathrm{L}$, the total clearance was $1.08 \pm 0.41$ $\mathrm{L} /$ hour, the volume of distribution was $41.97 \pm 22.64 \mathrm{~L}$, and the elimination half-life was $28.78 \pm 10.40$ hours.

Serum concentrations remained high at all times $\left(C_{\min }=1.54 \mathrm{mg} / \mathrm{L}\right)$ and were similar to those in healthy adult subjects and in patients with fungal infections.

The authors concluded that pharmacokinetics of anidulafungin during CVVHF resembled findings in healthy adults and in adults with fungal infections and they recommend loading doses of $200 \mathrm{mg}$ intravenous anidulafungin on the first day and $100 \mathrm{mg}$ on consecutive treatment days in patients during CVVHF.

Similar results were obtained by De Rosa and colleagues [72]. In this study, the pharmacokinetics of standard doses of anidulafungin were studied in two ICU patients with candidemia and septic shock undergoing CVVHF. Both patients had satisfactory parameters of $C_{\max }(9.04$ and $5.68 \mathrm{mg} / \mathrm{L}$, respectively), area under the curve (AUC; 95.18 and $67.48 \mathrm{mg} / \mathrm{L}$ hour), and $\mathrm{C}_{\min }$ (2.61 and $1.43 \mathrm{mg} / \mathrm{L}$ ). AUC/MIC ratio and $\mathrm{C}_{\max } / \mathrm{MIC}$ values were 11,887 and 8,435 (patient 1 ) and 1,130.25 and 710 (patient 2), respectively. According to these data, the authors concluded that anidulafungin presents only mild pharmacokinetic changes in septic shock patients undergoing CVVHF and no dose changes are needed.

\section{Micafungin}

In 2004, Kishino and colleagues [73] reported the first data on the use of micafungin and CRRT. These authors studied six living donor liver recipients, four of whom underwent CVVHF. Micafungin (40 to $50 \mathrm{mg}$ ) was administered once daily for 3 weeks after liver transplantation. On the third day after the start of the infusion, several blood samples were taken from points located proximal and distal to the hemofilter. Ultradiafiltrate samples were also collected. CVVHF was performed by using a $1.5-\mathrm{m}^{2}$ cellulose dialyzer. The ultrafiltrate was constantly obtained at $2,000 \mathrm{~mL} /$ hour by the postdilutional method. The mean $\mathrm{C}_{\max }$ and $\mathrm{C}_{\min }$ (trough) values of micafungin in plasma were $6.31 \pm 1.08$ and
$1.65 \pm 0.54 \mu \mathrm{g} / \mathrm{mL}$, respectively. The mean micafungin $\mathrm{C}_{\text {in }}-\mathrm{C}_{\text {out }}$ were very similar. The mean micafungin $\mathrm{C}_{\text {in }}-$ $\mathrm{C}_{\text {out }}$ and the clearance of micafungin were $0.96 \pm 0.04$ and $0.054 \pm 0.04 \mathrm{~mL} / \mathrm{min}$ per $\mathrm{kg}$, respectively, with 1.0 $\mathrm{mg}$ of the drug in the ultrafiltrate. The authors concluded that CVVHF had little effect on micafungin kinetics, and no dose adjustment or modification of dosing interval was needed during CVVHF.

Hirata and colleagues [43] evaluated the influence of continuous hemodiafiltration (CHDF) on the pharmacokinetics of micafungin in ICU patients. The authors studied four ICU patients receiving CHDF and nine ICU patients not receiving CHDF. CHDF was performed using a polymethyl methacrylate hollow-fiber membrane. Replacement fluid was delivered after the membrane into the venous limb of the circuit at a rate appropriate for the requirements of each patient. Standard dialysate was delivered at a rate of between 500 and $1,000 \mathrm{~mL} /$ hour. Blood samples were obtained before and after filtering, and urine samples and ultradiafiltrate samples were also collected for a steady-state assay of micafungin. The concentration of micafungin in serum was determined by high-performance liquid chromatography. Micafungin (dosage range, 150 to $300 \mathrm{mg} /$ day) was administered to patients regardless of whether they were receiving $\mathrm{CHDF}$. Finally, micafungin concentrations were available in three of the patients undergoing CHDF. In these three patients, mean micafungin concentrations at the inlet and outlet of the CHDF circuit were $12.7 \pm 10.2$ and $12.3 \pm 10.1 \mathrm{mg} / \mathrm{mL}$, respectively. Micafungin was not detected in the ultradiafiltrate, and urine concentration was $0.2 \pm 0.1 \mathrm{mg} / \mathrm{mL}$. The authors concluded that CHDF does not affect the pharmacokinetics of micafungin, so it is not necessary to adjust the micafungin dose in patients undergoing CHDF.

\section{Clinical significance of echinocandin drug adsorption}

In an assessment of the clinical significance of drug adsorption, five points must be considered.

First, it is essential to know the $\mathrm{pK} / \mathrm{pD}$ of the antibiotic $[74,75]$. For drugs that demonstrate timedependent activity, the antimicrobial effect is related to the length of time that plasma concentrations are above a threshold MIC. For those that exhibit concentrationdependent activity, the antimicrobial effect is related to the post-distribution $C_{\max }$ or the area under the concentration-time curve. If the area under the inhibitory curve is the most important parameter and the adsorption is completely reversible, adsorption should not affect antimicrobial activity. In contrast, when the $\mathrm{C}_{\max } / \mathrm{MIC}$ ratio is the best $\mathrm{pK} / \mathrm{pD}$ parameter for this antibiotic, even if the adsorption is reversible, the $\mathrm{C}_{\max }$ will be lower and antimicrobial activity could be compromised. 
Second, to predict the clinical significance, it is important to know the time course of adsorption and whether this adsorption is reversible. The length of time that a filter has been used may affect its adsorption. We should determine the extent of adsorption at first dose of antibiotic given to the patient when starting CRRT with a new filter and the effect of repeated doses over an already-saturated filter when the steady-state drug concentration has been reached.

Third, the absorption of a drug could differ significantly depending on the filter membrane material and surface area. In general, adsorption onto PAN filters is higher than onto other synthetic membranes $[59,60]$.

Fourth, the mode of CRRT could affect filter absorption capacity. A transmembrane pressure increase due to convection during hemofiltration would increase the hollow-fiber membrane's adsorption capacity compared with the capacity observed in hemodialysis. This is especially relevant in high-flux convection $[67,68]$.

Fifth, it is unclear whether differences in plasma $\mathrm{pH}$ and albumin concentration could affect drug adsorption. Antimicrobial activity depends on the fraction of unbound drug, and this fraction can be altered by many factors, such as systemic $\mathrm{pH}$, heparin therapy, hyperbilirubinemia, concentration of free fatty acids, relative concentration of drug and protein, and the presence of uremic products and other drugs with competitive mechanisms [66].

In light of the points discussed above, some comments about these studies follow. From the study on caspofungin [42], as the authors noted, the different extracorporeal clearances obtained by estimation from $C_{i n}-C_{\text {out }}$ and from $\mathrm{S}_{\mathrm{c}}$ suggest some adsorption of caspofungin by the hemofilter membrane. However, this adsorption appears to have no detectable effect on caspofungin plasma pharmacokinetics.

The study by Leitner and colleagues [36] demonstrates that anidulafungin adsorption reaches a plateau phase within 2 hours after first dosing. As a result, $\mathrm{C}_{\max }$ is likely to be reduced. A mean total amount of $19 \% \pm 6 \%$ of the anidulafungin in the arterial line was retained by absorption at the hollow-fiber dialyzer 2 hours after the first drug infusion. This adsorption to the polyethylene sulfone hemofilter seems to be saturable, and adsorption decreased over time. The authors concluded that there is no significant anidulafungin adsorption during CVVHF, so a standard dose can be recommended for patients on hemofiltration.

Some factors in the study by Kishino and colleagues [73] might influence the validity of their results with respect to the adsorption of micafungin. Micafungin concentrations were determined on the third day after the start of the infusion, when drug concentrations had already reached the steady state. Although the authors do not report whether the filter had been changed between the start of infusion and determinations, it is likely that it had not, so the membrane may very well have been completely saturated on the third day. Moreover, the cellulose membrane used has a low adsorptive capacity, and owing to poor biocompatibility in critically ill patients, cellulose membranes are no longer used in acute kidney injury. Finally, blood and ultrafiltration flows were low. All these factors could help explain why they found no drug loss due to adsorption.

The study by Hirata and colleagues [43] also has some methodological flaws. First, their data came from only three patients, and each of these apparently received different doses of micafungin. Moreover, replacement and dialysis flow varied based on the requirements of each patient. Finally and most importantly, the authors do not report how long the filters had been in use at the time of micafungin infusion or the number of doses administered before the concentration of the drug was determined.

\section{Final considerations}

The differences reported by the studies in the amount of adsorption of echinocandins onto the hemofilter membrane could result in controversy about the clinical significance of echinocandin adsorption. However, the discrepant results are most likely due to the disparate conditions and methodologies of the studies rather than to the differences between echinocandin molecules. Given the great similarities in the structure and protein binding of the echinocandins, it is highly likely that these three molecules would interact identically with the different hemofilter membranes. If comparative studies among the three echinocandins were done under the same circumstances (same mode of renal replacement, same membrane and surface area, same flows, and same times of determination with respect to the infusion of the drug and the hemofilter life), the amount of drug lost by adsorption would very probably be nearly identical. This proportion of drug (possibly up to $20 \%$ in the first dose) does not seem to be clinically relevant, at least not for anidulafungin and caspofungin, because these two drugs are administered in a loading dose to reach steady-state concentrations on the first day. However, in micafungin, the proportion of drug lost may be clinically relevant because, unlike the other two echinocandins, micafungin is not administered in a loading dose [2]. Thus, the plasmatic levels on the first day might be compromised by drug loss due to adsorption in a hemofilter that is not yet saturated, especially when high-adsorptive capacity membranes and medium- to high-volume convection flows are used, as is recommended in critically unstable patients with severe sepsis and multiorgan dysfunction. Given the above, the removal of echinocandins by adsorption to the synthetic surfaces of hemofilters is unlikely to have clinical relevance once the steady-state concentration is reached. 
For all echinocandins, it is unknown whether repeated hemofilter clotting and filter half-life of less than 24 hours could affect the fungicidal activity of echinocandins, so further studies are required. One major limitation in all of the studies referred to is the small size and the heterogeneity of the study population. Moreover, it is essential to use a validated technique to measure drug concentrations because the difference between pre- and post-filter concentrations may be very small, so caution is warranted in all studies.

\section{Conclusions}

The removal of echinocandins by adsorption to the synthetic surfaces of hemofilters is unlikely to have clinical relevance once the steady-state concentration is reached.

\author{
Abbreviations \\ $A \cup C$ : area under the curve; $\mathrm{AUC}_{0-24}$ : area under the curve over 24-hour dos- \\ ing interval; AV: arteriovenous; CHDF: continuous hemodiafiltration; \\ $C_{\text {in }}-C_{\text {out }}$ : concentrations in the hemofilter/dialyzer inlet and outlet; \\ CLHD: hemodialysis clearance; CLHF: hemofiltration clearance; \\ $C_{\text {max }}$ : maximum concentration; $C_{\text {min }}$ : minimum concentration; \\ CRRT: continuous renal replacement therapy; CWHD: continuous \\ venovenous hemodialysis; CWHF: continuous venovenous hemofiltration; \\ MIC: minimum inhibitory concentration; PAN: polyacrylonitrile; \\ pD: pharmacodynamic; pK: pharmacokinetic; $S_{c}$ : sieving coefficient; \\ $\mathrm{S}_{\mathrm{d}}$ : saturation coefficient.
}

\section{Competing interests}

FJGdM has received honoraria from Astellas (Tokyo, Japan), MSD (Whitehouse Station, NJ, USA), Pfizer (New York, NY, USA), and GambroHospal (Lund, Sweden). MAM-A declares that he has no competing interests. RF has received honoraria from MSD and Pfizer.

\section{Authors' contributions}

All authors made a substantial contribution to the manuscript. MAM-A and RF helped to review the literature and critically revised the manuscript for important intellectual content. FJGdM helped to review the literature and drafted the manuscript. All authors read and approved the final manuscript.

\section{Acknowledgments}

The authors would like to acknowledge the writing assistance of John Giba.

Published: 28 March 2014

\section{References}

1. Denning DW: Echinocandin antifungal drugs. Lancet 2003, 362:1142-1151.

2. Chen SC, Slavin MA, Sorrell TC: Echinocandin antifungal drugs in fungal infections: a comparison. Drugs 2011, 71:11-41.

3. Mikamo H, Sato Y, Tamaya T: In vitro antifungal activity of FK463, a new water-soluble echinocandin-like lipopeptide. J Antimicrob Chemother 2000, 46:485-487.

4. Taft CS, Selitrennikoff CP: Cilofungin inhibition of (1-3)-beta-glucan synthase: the lipophilic side chain is essential for inhibition of enzyme activity. J Antibiot (Tokyo) 1990, 43:433-437.

5. Wiederhold NP, Lewis RE: The echinocandin antifungals: an overview of the pharmacology, spectrum and clinical efficacy. Expert Opin Investig Drugs 2003, 12:1313-1333.

6. Pappas PG, Kauffman CA, Andes D, Benjamin DK Jr, Calandra TF, Edwards JE Jr, Filler SG, Fisher JF, Kullberg BJ, Ostrosky-Zeichner L, Reboli AC, Rex JH, Walsh TJ, Sobel JD, Infectious Diseases Society of America: Clinical practice guidelines for the management of candidiasis: 2009 update by the Infectious Diseases Society of America. Clin Infect Dis 2009, 48:503-535.

7. Douglas CM: Fungal beta(1,3)-D-glucan synthesis. Med Mycol 2001, 39:55-66.
8. Odds FC, Brown AJ, Gow NA: Antifungal agents: mechanisms of action. Trends Microbiol 2003, 11:272-279.

9. Sucher AJ, Chahine EB, Balcer HE: Echinocandins: the newest class of antifungals. Ann Pharmacother 2009, 43:1647-1657.

10. Pfaller MA, Boyken L, Hollis RJ, Kroeger J, Messer SA, Tendolkar S, Diekema DJ: In vitro susceptibility of invasive isolates of Candida spp. to anidulafungin, caspofungin, and micafungin: six years of global surveillance. J Clin Microbiol 2008, 46:150-156.

11. Ostrosky-Zeichner L, Rex JH, Pappas PG, Hamill RJ, Larsen RA, Horowitz HW, Powderly WG, Hyslop N, Kauffman CA, Cleary J, Mangino JE, Lee J: Antifungal susceptibility survey of 2,000 bloodstream Candida isolates in the United States. Antimicrob Agents Chemother 2003, 47:3149-3154.

12. Pfaller MA: Antifungal drug resistance: mechanisms, epidemiology, and consequences for treatment. Am J Med 2012, 125:S3-S13.

13. Andes D, Diekema DJ, Pfaller MA, Bohrmuller J, Marchillo K, Lepak A: In vivo comparison of the pharmacodynamic targets for echinocandin drugs against Candida species. Antimicrob Agents Chemother 2010, 54:2497-2506.

14. Theuretzbacher U: Pharmacokinetics/pharmacodynamics of echinocandins. Eur J Clin Microbiol Infect Dis 2004, 23:805-812.

15. Pound MW, Townsend ML, Drew RH: Echinocandin pharmacodynamics: review and clinical implications. J Antimicrob Chemother 2010, 65:1108-1118.

16. Cappelletty D, Eiselstein-McKitrick K: The echinocandins. Pharmacotherapy 2007, 27:369-388.

17. Boucher HW, Groll AH, Chiou CC, Walsh TJ: Newer systemic antifungal agents: pharmacokinetics, safety and efficacy. Drugs 2004, 64:1997-2020.

18. Kofla G, Ruhnke M: Pharmacology and metabolism of anidulafungin, caspofungin and micafungin in the treatment of invasive candidosis: review of the literature. Eur J Med Res 2011, 16:159-166.

19. Uchino S, Kellum JA, Bellomo R, Doig GS, Morimatsu H, Morgera S, Schetz M, Tan I, Bouman C, Macedo E, Gibney N, Tolwani A, Ronco C, Beginning and Ending Supportive Therapy for the Kidney (BEST Kidney) Investigators: Acute renal failure in critically ill patients: a multinational, multicenter study. JAMA 2005, 294:813-818.

20. Murugan R, Kellum JA: Acute kidney injury: what's the prognosis? Nat Rev Nephrol 2011, 7:209-217.

21. Bagshaw SM, George C, Bellomo R, Committee ADM: Early acute kidney injury and sepsis: a multicentre evaluation. Crit Care 2008, 12:R47.

22. Parmar A, Langenberg C, Wan L, May CN, Bellomo R, Bagshaw SM: Epidemiology of septic acute kidney injury. Curr Drug Targets 2009, 10:1169-1178.

23. Hoste EA, Schurgers M: Epidemiology of acute kidney injury: how big is the problem? Crit Care Med 2008, 36:S146-S151.

24. Reynvoet E, Vandijck DM, Blot SI, Dhondt AW, De Waele JJ, Claus S, Buyle FM, Vanholder RC, Hoste EA: Epidemiology of infection in critically ill patients with acute renal failure. Crit Care Med 2009, 37:2203-2209.

25. Macedo E, Bouchard J, Mehta RL: Renal replacement therapy for acute renal failure. Minerva Urol Nefrol 2009, 61:189-204.

26. Roberts JA, Lipman J: Pharmacokinetic issues for antibiotics in the critically ill patient. Crit Care Med 2009, 37:840-851. quiz 859.

27. Heintz BH, Matzke GR, Dager WE: Antimicrobial dosing concepts and recommendations for critically ill adult patients receiving continuous renal replacement therapy or intermittent hemodialysis. Pharmacotherapy 2009, 29:562-577.

28. Bugge JF: Influence of renal replacement therapy on pharmacokinetics in critically ill patients. Best Pract Res Clin Anaesthesiol 2004, 18:175-187.

29. Choi G, Gomersall CD, Tian Q, Joynt GM, Freebairn R, Lipman J: Principles of antibacterial dosing in continuous renal replacement therapy. Crit Care Med 2009, 37:2268-2282.

30. Schetz M: Drug dosing in continuous renal replacement therapy: general rules. Curr Opin Crit Care 2007, 13:645-651.

31. Trotman RL, Williamson JC, Shoemaker DM, Salzer WL: Antibiotic dosing in critically ill adult patients receiving continuous renal replacement therapy. Clin Infect Dis 2005, 41:1159-1166.

32. John S, Eckardt KU: Renal replacement strategies in the ICU. Chest 2007, 132:1379-1388.

33. Forni LG, Hilton PJ: Continuous hemofiltration in the treatment of acute renal failure. N Engl J Med 1997, 336:1303-1309.

34. Clark WR, Ronco C: Continuous renal replacement techniques. Contrib Nephrol 2004, 144:264-277.

35. Perego AF: Adsorption techniques: dialysis sorbents and membranes. Blood Purif 2013, 35:48-51. 
36. Leitner JM, Meyer B, Fuhrmann V, Saria K, Zuba C, Jager W, Bohmdorfer M, Thalhammer F: Multiple-dose pharmacokinetics of anidulafungin during continuous venovenous haemofiltration. J Antimicrob Chemother 2011, 66:880-884.

37. Choi G, Gomersall CD, Lipman J, Wong A, Joynt GM, Leung P, Ramsay SJ, Ho OM: The effect of adsorption, filter material and point of dilution on antibiotic elimination by haemofiltration: an in vitro study of levofloxacin. Int J Antimicrob Agents 2004, 24:468-472.

38. Tian Q, Gomersall CD, Ip M, Tan PE, Joynt GM, Choi GY: Adsorption of amikacin, a significant mechanism of elimination by hemofiltration. Antimicrob Agents Chemother 2008, 52:1009-1013.

39. Tian Q, Gomersall CD, Wong A, Leung P, Choi G, Joynt GM, Tan P, Lipman J: Effect of drug concentration on adsorption of levofloxacin by polyacrylonitrile haemofilters. Int J Antimicrob Agents 2006, 28:147-150.

40. Tian Q, Gomersall CD, Leung PP, Choi GY, Joynt GM, Tan PE, Wong AS: The adsorption of vancomycin by polyacrylonitrile, polyamide, and polysulfone hemofilters. Artif Organs 2008, 32:81-84.

41. Wagner CC, Steiner I, Zeitlinger M: Daptomycin elimination by CVVH in vitro: evaluation of factors influencing sieving and membrane adsorption. Int J Clin Pharmacol Ther 2009, 47:178-186.

42. Weiler S, Seger C, Pfisterer H, Stienecke E, Stippler F, Welte R, Joannidis M, Griesmacher A, Bellmann R: Pharmacokinetics of caspofungin in critically ill patients on continuous renal replacement therapy. Antimicrob Agents Chemother 2013, 57:4053-4057.

43. Hirata K, Aoyama T, Matsumoto Y, Ogawa F, Yamazaki H, Kikuti A, Yamamoto $Y$ : Pharmacokinetics of antifungal agent micafungin in critically ill patients receiving continuous hemodialysis filtration. Yakugaku Zasshi 2007, 127:897-901.

44. Markou N, Fousteri M, Markantonis SL, Zidianakis B, Hroni D, Boutzouka E, Baltopoulos G: Colistin pharmacokinetics in intensive care unit patients on continuous venovenous haemodiafiltration: an observational study. J Antimicrob Chemother 2012, 67:2459-2462.

45. Atan R, Crosbie D, Bellomo R: Techniques of extracorporeal cytokine removal: a systematic review of the literature. Blood Purif 2012, 33:88-100.

46. Cole L, Bellomo R, Davenport P, Tipping P, Uchino S, Tetta C, Ronco C: The effect of coupled haemofiltration and adsorption on inflammatory cytokines in an ex vivo model. Nephrol Dial Transplant 2002, 17:1950-1956.

47. Matsumura Y, Oda S, Sadahiro T, Nakamura M, Hirayama Y, Watanabe E, Abe R, Nakada TA, Tateishi Y, Oshima T, Shinozaki K, Hirasawa H: Treatment of septic shock with continuous HDF using 2 PMMA hemofilters for enhanced intensity. Int J Artif Organs 2012, 35:3-14.

48. Tetta C, Bellomo R, Inguaggiato P, Wratten ML, Ronco C: Endotoxin and cytokine removal in sepsis. Ther Apher 2002, 6:109-115.

49. Weerwind PW, van der Veen FH, Gelsomino S, Nagaraj NG, Parise O, Lorusso R, Gensini GF, Maessen JG: Cytokine removal on extracorporeal life support for treatment of acute endotoxemia: a randomized controlled animal study. Int J Cardiol 2013, 168:4699-4704.

50. Shimizu T, Obata T, Sonoda H, Akabori H, Tabata T, Eguchi Y, Endo Y, Tani T: The ability of endotoxin adsorption during a longer duration of direct hemoperfusion with a polymyxin B-immobilized fiber column in patients with septic shock. Transfus Apher Sci 2013, 49:499-503.

51. Panagiotou A, Gaiao S, Cruz DN: Extracorporeal therapies in sepsis. J Intensive Care Med 2013, 28:281-295.

52. Hirasawa H, Oda S, Nakamura M, Watanabe E, Shiga H, Matsuda K: Continuous hemodiafiltration with a cytokine-adsorbing hemofilter for sepsis. Blood Purif 2012, 34:164-170.

53. Bugge JF: Pharmacokinetics and drug dosing adjustments during continuous venovenous hemofiltration or hemodiafiltration in critically ill patients. Acta Anaesthesio/ Scand 2001, 45:929-934.

54. Bouman CS: Antimicrobial dosing strategies in critically ill patients with acute kidney injury and high-dose continuous veno-venous hemofiltration. Curr Opin Crit Care 2008, 14:654-659.

55. Alexander $\mathrm{E}$ : Antibiotic dosing and concentration variability during continuous renal replacement therapy: is status quo good enough? Crit Care Med 2012, 40:1671-1672.

56. Swinford RD, Baid S, Pascual M: Dialysis membrane adsorption during CRRT. Am J Kidney Dis 1997, 30:S32-S37.

57. Moachon N, Boullange C, Fraud S, Vial E, Thomas M, Quash G: Influence of the charge of low molecular weight proteins on their efficacy of filtration and/or adsorption on dialysis membranes with different intrinsic properties. Biomaterials 2002, 23:651-658.
58. Goldman M, Lagmiche M, Dhaene M, Amraoui Z, Thayse C, Vanherweghem JL: Adsorption of beta 2-microglobulin on dialysis membranes: comparison of different dialyzers and effects of reuse procedures. Int J Artif Organs 1989, 12:373-378.

59. Clark WR, Hamburger RJ, Lysaght MJ: Effect of membrane composition and structure on solute removal and biocompatibility in hemodialysis. Kidney Int 1999, 56:2005-2015.

60. Davenport A: Membrane designs and composition for hemodialysis, hemofiltration and hemodialfiltration: past, present and future. Minerva Urol Nefrol 2010, 62:29-40.

61. Honore PM, Jacobs R, Joannes-Boyau O, De Regt J, De Waele E, van Gorp V, Boer W, Verfaillie L, Spapen HD: Newly designed CRRT membranes for sepsis and SIRS - a pragmatic approach for bedside intensivists summarizing the more recent advances: a systematic structured review. ASAIO J 2013, 59:99-106.

62. Kraft $\mathrm{D}$, Lode $\mathrm{H}$ : Elimination of ampicillin and gentamicin by hemofiltration. Klin Wochenschr 1979, 57:195-196.

63. Kronfol NO, Lau AH, Barakat MM: Aminoglycoside binding to polyacrylonitrile hemofilter membranes during continuous hemofiltration. ASAIO Trans 1987, 33:300-303.

64. Thomas M, Moriyama K, Ledebo I: AN69: Evolution of the world's first high permeability membrane. Contrib Nephrol 2011, 173:119-129.

65. Wright JD, Boudinot FD, Ujhelyi MR: Measurement and analysis of unbound drug concentrations. Clin Pharmacokinet 1996, 30:445-462.

66. Kunin CM: Clinical pharmacology of the new penicillins. 1. The importance of serum protein binding in determining antimicrobial activity and concentration in serum. Clin Pharmacol Ther 1966, 7:166-179.

67. Pedrini LA, Cozzi G, Faranna P, Mercieri A, Ruggiero P, Zerbi S, Feliciani A, Riva A: Transmembrane pressure modulation in high-volume mixed hemodiafiltration to optimize efficiency and minimize protein loss. Kidney Int 2006, 69:573-579.

68. Ahrenholz PG, Winkler RE, Michelsen A, Lang DA, Bowry SK: Dialysis membrane-dependent removal of middle molecules during hemodiafiltration: the beta2-microglobulin/albumin relationship. Clin Nephrol 2004, 62:21-28.

69. Stone JA, Holland SD, Wickersham PJ, Sterrett A, Schwartz M, Bonfiglio C, Hesney M, Winchell GA, Deutsch PJ, Greenberg H, Hunt TL, Waldman SA: Single- and multiple-dose pharmacokinetics of caspofungin in healthy men. Antimicrob Agents Chemother 2002, 46:739-745.

70. Liu P, Ruhnke M, Meersseman W, Paiva JA, Kantecki M, Damle B: Pharmacokinetics of anidulafungin in critically ill patients with candidemia/invasive candidiasis. Antimicrob Agents Chemother 2013, 57:1672-1676.

71. Hiemenz J, Cagnoni P, Simpson D, Devine S, Chao N, Keirns J, Lau W, Facklam D, Buell D: Pharmacokinetic and maximum tolerated dose study of micafungin in combination with fluconazole versus fluconazole alone for prophylaxis of fungal infections in adult patients undergoing a bone marrow or peripheral stem cell transplant. Antimicrob Agents Chemother 2005, 49:1331-1336.

72. De Rosa FG, Corcione S, Baietto L, Pasero D, Perri GD, Ranieri VM, D'Avolio A: Pharmacokinetics of anidulafungin in two critically ill patients with septic shock undergoing CVVH. J Chemother 2013, 25:376-378.

73. Kishino S, Ohno K, Shimamura T, Furukawatodo H: Optimal prophylactic dosage and disposition of micafungin in living donor liver recipients. Clin Transplant 2004, 18:676-680.

74. Sinnollareddy M, Peake SL, Roberts MS, Lipman J, Roberts JA: Using pharmacokinetics and pharmacodynamics to optimise dosing of antifungal agents in critically ill patients: a systematic review. Int J Antimicrob Agents 2012, 39:1-10.

75. Roberts JA, Joynt GM, Choi GY, Gomersall CD, Lipman J: How to optimise antimicrobial prescriptions in the intensive care unit: principles of individualised dosing using pharmacokinetics and pharmacodynamics. Int J Antimicrob Agents 2012, 39:187-192.

doi:10.1186/cc13803

Cite this article as: González de Molina et al:: Treatment with echinocandins during continuous renal replacement therapy. Critical Care 2014 18:218. 